\title{
Cohabiting Partners' Socioeconomic Characteristics and the Transition to Marriage in Finland
}

\author{
ELINA MÄENPÄÄ, M.Soc.Sc., Researcher \\ Population Research Unit, Department of Sociology, University of Helsinki
}

\begin{abstract}
This study analyzes how the socioeconomic positions of cohabiting partners affect the transition to marriage by using information on both partners' characteristics. The study uses a register-based data set compiled at Statistics Finland. The study population consists of 3,648 women born in 1966-1971 who were in a cohabiting union in January 1996, and who continued to cohabit or married their cohabiting partner during the period 1996-2003. Transition to marriage was analyzed with Cox regression model. Several control variables were included. As in previous studies, a favourable socioeconomic position encouraged marriage, as marriage rate increased with higher levels of education and income. Partners' relative positions also had importance, since marriage rate was low when the female partner had high and the male partner low income, and the male partner's unemployment discouraged marriage especially when the female partner had no unemployment. Marriage rate was low when both partners were studying.
\end{abstract}

Keywords: cohabiting unions, marriage, socioeconomic position, register data, Finland

\section{Introduction}

During the last few decades, cohabiting unions have become increasingly common in the Nordic countries, including Finland. Cohabitation no longer necessarily leads to marriage or separation in a relatively short period of time, but can also be a long-term alternative to marriage (see Jalovaara 2007, 17). Nonetheless, marriage remains a strong institution, and many couples still choose marriage as a form of union. Therefore, it has become important to ask what are the factors affecting the cohabiting couple's choice of marrying. Examining these factors can also shed light on the question how cohabitation and marriage differ from each other as union types. This study analyzes how the socioeconomic characteristics of cohabiting partners affect the transition to marriage in Finland. 


\section{Trends in cohabitation and marriage in Finland}

The rise in cohabitation and a fall in marriage rates - typical indicators of the so-called second demographic transition - have emerged in Finland since the 1970s. Not only has the mean age at first marriage for women risen from 23.7 years in the period 1971-1980 to 29.3 years in 2001-2005, but also total first marriage rates for cohorts have declined (Pitkänen and Jalovaara 2007). On the other hand, the proportion of cohabiting couples of all couples living in a union has risen steadily during the same period (see Figure 1). In 2005, almost one in four couples was a cohabiting couple.

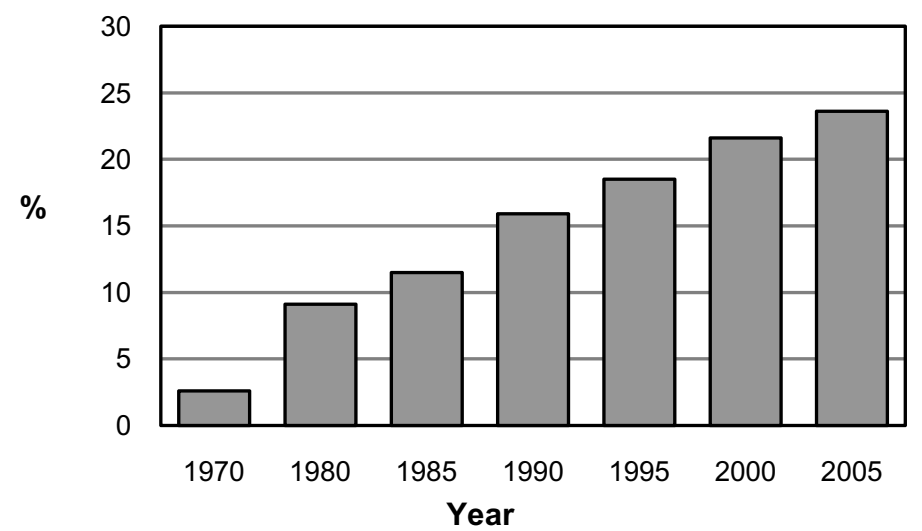

Figure 1. Proportion of cohabiting couples of all couples living in a union in Finland 1970-2005.

Source: Pitkänen and Jalovaara 2007, Table 5.4.

Cohabitation has become a common way to start a union. Only a fraction of couples nowadays marry before they move in together. The link between having children and marrying has also weakened: the proportion of children born outside marriage - a great majority of them to cohabiting parents - has risen steeply since the 1970s and is now around 40 percent (Ruokolainen and Notkola 2007). Children are not only born to but also raised by many cohabiting couples, and an increasing proportion of cohabiting unions can be viewed as social substitutes for marriage (see Jalovaara $2007,17)$. However, cohabitation is still common especially among young people. In 2005, cohabiting was more common than being married among persons aged 25-29 and younger, and starting from age group 30-34, it was more common to be married than in a cohabiting union. (Pitkänen and Jalovaara 2007.)

\section{Theoretical background and results from previous studies}

It has often been suggested that a relatively firm economic foundation is required for making the transition from cohabitation to marriage. Individuals are expected to display potentials for a stable economic future to be considered worthy of a strong commitment. 
There may be expectations from friends, family, or less identifiable source about proper behaviour in marriage, such as a higher material standard of living (e.g. home ownership), completion of schooling, and economic independence from parents. The entry into marriage can also involve immediate financial expenses if a large wedding party is wanted or expected. (Thornton et al. 1995; Clarkberg 1999; Kravdal 1999; Smock et al. 2005.)

Main finding in previous studies on the effects of individual's socioeconomic traits on marriage is that a high socioeconomic position, especially the male partner's, does promote marriage. The male partner's higher educational level (Bracher and Santow 1998; Duvander 1999; Kravdal 1999; Wu and Pollard 2000) as well as higher income (Smock and Manning 1997; Sanchez et al. 1998) have consistently been reported to increase the probability of marriage. Male partner's employment has also been found to increase the marriage rate (Manning and Smock 1995; Smock and Manning 1997; Kravdal 1999), although Bracher and Santow (1998) did not find a connection to marriage.

The female partner's educational level has been reported to encourage marriage in the Nordic countries (Finnäs 1995; Bracher and Santow 1998; Kravdal 1999), whereas no effect has been found in North America (Manning and Smock 1995; Wu and Balakrishnan 1995; Smock and Manning 1997). A positive association between the female partner's income and marriage has been reported in Norway (Kravdal 1999), but not in the United States (Smock and Manning 1997; Sanchez et al. 1998). Marriage rate has consistently been found to be low among cohabiting unions where the female partner is studying (Wu and Balakrishnan 1995; Bracher and Santow 1998; Kravdal 1999; Müller 2003).

The socioeconomic characteristics of the cohabiting partners can also have joint effects on the transition to marriage that are based on the presumed differences between cohabitation and marriage as union types. On the grounds of various studies, it can be argued that marriage is a more traditional union type than cohabitation, in that it is associated with more positive attitudes towards the traditional division of labour in the household, with the female partner being the homemaker and the male partner the breadwinner. For example, in Duvander's (1999) Swedish study, women who preferred a traditional division of labour had a higher propensity to marry their cohabiting partner, and in a study from the US (Clarkberg et al. 1995), egalitarian gender role attitudes increased the probability of the first union being cohabitation as opposed to marriage. Cohabiting couples also tend to share household tasks in a more egalitarian way than married couples (Blair and Lichter 1991; Davis et al. 2007).

If this assumption that the choice of union type is associated with the couple's attitudes towards the traditional division of labour is correct, it can be expected that this appears also in the combinations of the partners' socioeconomic positions: couples choosing marriage would be more likely than couples preferring cohabitation to follow the conventional pattern of the male partner being in a higher socioeconomic position than the female partner. Thus, it can be hypothesized that the male partner's higher socio- 
economic position would increase the probability of proceeding from cohabitation to marriage. A study by Manning and Smock (2002) supports this view and reported that if the female cohabiting partner had a higher level of education or higher income than the male partner, the female partner's expectations of marriage were lower.

Similarity or dissimilarity in general in the cohabiting partners' characteristics, that is, homogamy and heterogamy, can also have effect on the transition to marriage. Blackwell and Lichter $(2000,2004)$ suggest that cohabitation is less selective of the partner's characteristics than marriage, and that it provides a staging ground for evaluating potential marital partners and fostering better matches in marriage. Partners who are well matched, that is, more homogamous, would thus be more likely to progress from cohabitation to marriage. Blackwell and Lichter (2000) found marital unions to be more homogamous than cohabiting unions in e.g. educational level, but the results were based on an analysis of the characteristics of couples in different types of unions, not on the analysis of the transition from cohabitation to marriage.

There is relatively plenty of research on the topic of how individual's socioeconomic position affects the transition from cohabitation to marriage, but notably less is known about the potential interactive effects of the partners' socioeconomic characteristics. There is also scarce information on the factors that affect cohabiting couples' chances of marrying in Finland. The aim of this study is to find out how cohabiting partners' socioeconomic characteristics and their combinations between the partners affect the transition from cohabitation to marriage in Finland. The study is based on the author's unpublished master's thesis in demography (Mäenpää 2007).

\section{Data}

The data used in the study is an 11 percent random sample from the Palapeli research register compiled at Statistics Finland. The data set is individual-level and longitudinal, and it encompasses all individuals in the population of Finland between years 1970 and 2000 , and a follow-up of data from 2001 to 2003 . The research register has been formed by linking information from the person register and e.g. censuses and employment statistics by means of personal identity codes. In addition to marital unions, the Palapeli research register also includes cohabiting unions, which have been identified through register information on internal migration. Cohabiting couples are defined as a male and a female with no more than 20 years of age difference, who are not siblings or a parent and a child, and who have been domiciled in the same apartment for over 90 days. Dates of the formation and dissolution of unions are presented at the accuracy of a month.

So far no extensive and up-to-date research data on cohabiting unions has been available in Finland. What in addition makes the data set unique is that it provides information on both partners' characteristics and hence enables the study of potential interactive effects of the partners' traits. 
The study population consists of women born in 1966-1971 who were in a cohabiting union in January 1996. From these women, those who continued to cohabit or married their cohabiting partner during the eight-year follow-up period 1996-2003, were selected into the analysis. Women were 24-30-year-olds at the beginning of the follow-up; no restrictions were set on the partner's age besides the research register's limitation of 20 years maximum age difference between cohabiting partners. Age group 24-30 was selected because the aim was to study those unions that most likely are entered with a view to begin family formation.

Only unions where both partners were born in Finland were selected to the study population due to the large amount of missing data among persons born abroad. Unions where either partner was married at the beginning of the follow-up were left out of the analysis since marrying each other was not possible for these couples before the potential divorce coming into force. All cases with missing values on the variables used in the study were excluded from the analysis (in the case of time-dependent covariates, all cases with missing values during the exposure to risk), which reduced the size of the study population by three percent. The final size of the study population was 3,648 cohabiting unions.

Cohabiting unions that were selected from the Palapeli research register as described above also included 1,765 cohabitations that ended in separation during the follow-up. These cases were, however, left out of this analysis in order to compare those cohabiting unions that led to marriage to more permanent cohabiting unions that more likely could be viewed as social substitutes to marriage.

2,107 couples ( 57.8 percent of the study population) married during the eight-year follow-up period and 1,541 couples (42.2\%) continued to live in cohabitation. The mean age at marriage was 29.3 years for women and 31.5 for men.

\section{Socioeconomic characteristics}

Five indicators of the cohabiting partners' socioeconomic positions are included in the analysis: level of education, changes in the educational levels during the cohabiting union, unemployment, occupational activity, and income. In all characteristics, categories of the variables describe the different combinations of the partners' characteristics, except in the changes in educational levels.

\section{Level of education}

Level of education can be seen to represent the partners' long-term economic prospects. Partners' educational levels are the highest educational qualifications achieved by the entry into the cohabiting union. Educational levels were classified into three categories: basic, upper secondary and tertiary. Persons with no information on completed degrees in Statistics Finland's Register of Completed Education and Degrees are interpreted to have a basic-level qualification, which means at most nine years of education. Upper secondary level of education lasts 11 to 12 years, and includes e.g. the matriculation 
examination. Tertiary level of education includes lowest level tertiary education (2-3 years after upper secondary education), lower-degree level tertiary education (3-4 years after upper secondary education), higher-degree level tertiary education (5-6 years after upper secondary education), as well as doctorate or equivalent level tertiary education.

\section{Changes in the educational levels during the cohabiting union}

As partners' levels of education have been measured at the beginning of the union, this variable considers the potential changes in educational levels during the cohabiting union. According to Tzeng $(1992,610)$, changes in the partners' characteristics can alter the balance of power in the relationship and create tensions between the partners. On the other hand, changes that make the union more homogamous can be beneficial to the union (see Tzeng 1992). Changes have usually been thought to affect the dissolution of the union, but this study investigates whether changes in educational levels can have an effect on the transition to marriage.

First category of the variable consists of those couples whose educational levels have not changed. Second category comprises couples where both partners' educational level has increased, but no change in partners' relative positions has occurred. The third and fourth group consist of couples who have become educationally more homogamous; in the third group the educational level of the female partner has increased more, and in the fourth that of the male partner. In the last two categories the partners have become more heterogamous; in the fifth group through a greater increase in the educational level of the female partner, and in the sixth through that of the male partner. Couples who have remained heterogamous but the relative positions of the partners have reversed, that is, if a partner who had a basic level education at entry into the union has completed a tertiary level education whereas the other partner has maintained an upper secondary level education, have been placed in the last two categories.

\section{Unemployment}

Unemployment describes the cohabiting partners' cumulated socioeconomic disadvantage. Three-year moving averages of the partners' yearly months of unemployment were calculated and classified into three categories: no unemployment, maximum six months of unemployment per year and over six months of unemployment per year. The variable is used in the regression models as a time-dependent covariate, and the explanatory value is the combination of the partners' average months of unemployment during the year of marriage and two years preceding it.

\section{Occupational activity}

Analyzing the partners' occupational activities can clarify how the partners' short-term economic activity affects the transition to marriage. Information on occupational activity is obtained at Statistics Finland by examining multiple register data on the person's qualities in the last week of the year. Three categories of occupational activity are assorted: 
employed, student and other. The category 'other' is quite heterogeneous, and includes e.g. unemployed persons, pensioners, conscripts, and those originally classified as others, including persons performing domestic work. The variable is used in the regression models as a time-dependent covariate, and the explanatory value is the combination of the partners' occupational activities at the end of the year preceding marriage.

\section{Income}

Income is the most direct indicator of the partners' current economic resources. The measure of income used in the study is the partners' yearly incomes subject to state taxation. Income subject to state taxation includes e.g. wage income, entrepreneurial income, and certain social security benefits, such as unemployment benefits. Scholarships and grants received from public corporations for studies or research, part of income earned abroad, part of social security benefits, and tax-exempt interest income are not subject to state taxation. The variable is classified in three categories: $0-11,900$ $\epsilon$ per year, 12,000-22,400 $\epsilon$ per year and 22,500 $€$ or more per year. The categories are called low, medium and high income in the analysis. The variable is used in the regression models as a time-dependent covariate, and the explanatory value is the combination of the partners' income groups in the year preceding marriage.

Distributions of the socioeconomic variables in the study population are presented in Table 1. In the case of time-dependent covariates, which can change over time, distributions near the beginning of the follow-up period are presented.

\section{Control variables}

The Palapeli research register provides wide-ranging information on the individuals in the sample and their partners. Thereby various aspects of the sociodemographic characteristics and social background of the cohabiting partners that possibly affect the relationship between the partners' socioeconomic characteristics and the transition to marriage were controlled for in the analysis. The control variables are presented in Appendix 1.

\section{Method}

The method of analysis is Cox regression model (Cox 1972) with time-dependent covariates. The method takes into consideration both the frequency and the timing of the event, in this case, marriage. The model can be expressed by

$$
h(t)=\lambda_{0}(t) e^{\beta \mathbf{x}(t)},
$$

where $h(t)$ is the hazard of marriage at duration $t, \lambda_{0}(t)$ is an unspecified baseline hazard function, $\boldsymbol{\beta}$ is the vector of regression parameters associated with the explanatory variables included in the model, and $\mathbf{x}(t)$ is the vector of the explanatory variables. 
Table 1. Distributions of the socioeconomic variables in the study population and the percentage of couples who married during the follow-up period.

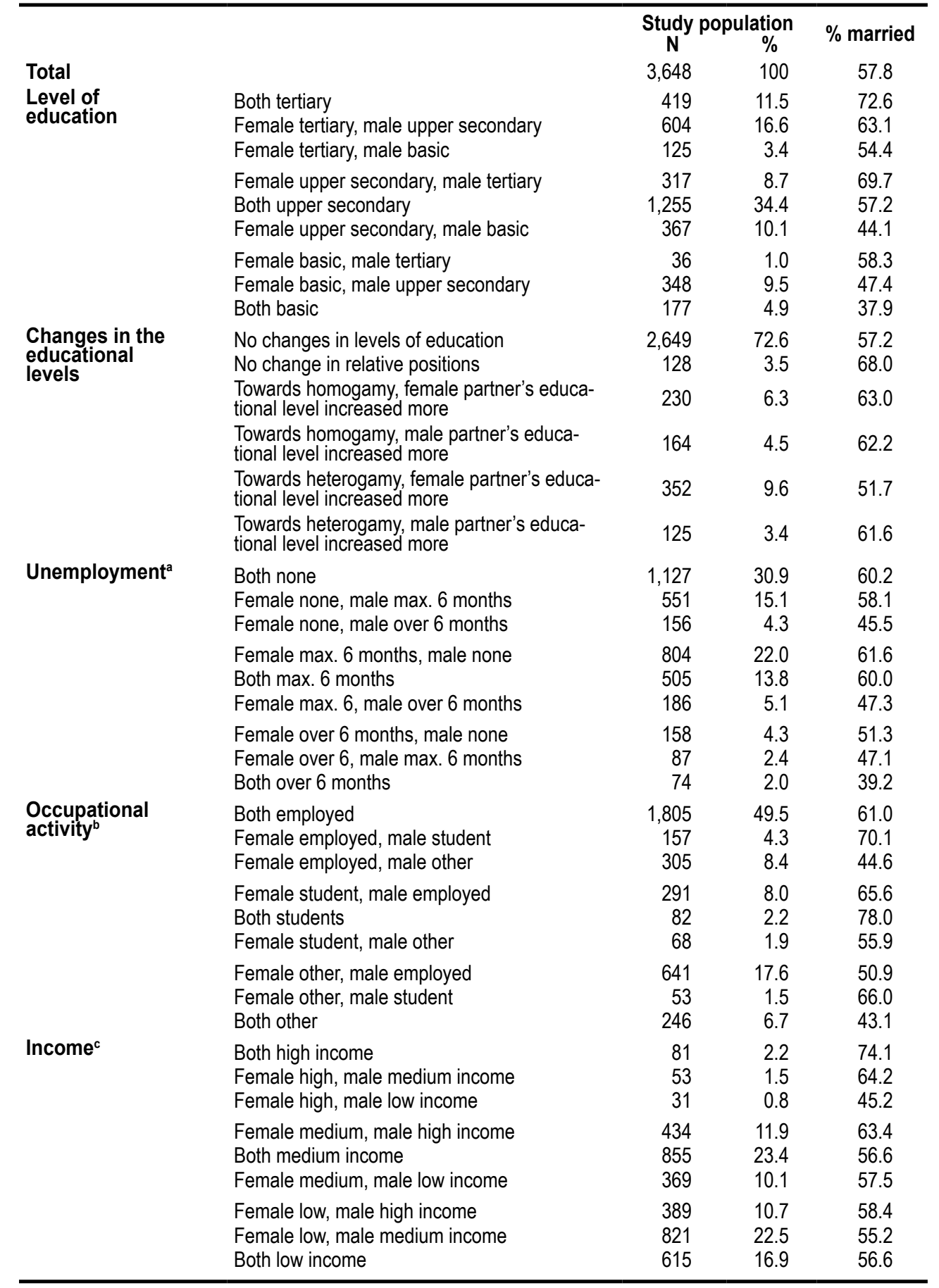

${ }^{a}$ Average months of unemployment during 1994-96 (time-dependent covariate).

${ }^{b}$ Occupational activity at the end of 1995 (time-dependent covariate).

${ }^{c}$ Income in 1995 (time-dependent covariate). 
Table 2. Hazard ratios of the transition to marriage $\left(\mathrm{e}^{\beta}\right)$ by the cohabiting partners' socioeconomic characteristics. Hazards deviating statistically significantly from the reference category's hazard in bold.

\begin{tabular}{|c|c|c|c|c|c|}
\hline \multirow{3}{*}{$\begin{array}{l}\text { Level of } \\
\text { education }\end{array}$} & \multirow[b]{3}{*}{$\begin{array}{l}\text { Both tertiary } \\
\text { Female tertiary, male upper secondary } \\
\text { Female tertiary, male basic }\end{array}$} & \multirow{2}{*}{\multicolumn{2}{|c|}{$\begin{array}{l}\text { Unadjusted effect } \\
e^{\beta} \quad 95 \% \mathrm{Cl}\end{array}$}} & \multicolumn{2}{|c|}{ Adjusted effect ${ }^{a}$} \\
\hline & & & & $e^{\beta}$ & \\
\hline & & $\begin{array}{l}1.61 \\
1.16 \\
0.93\end{array}$ & $\begin{array}{l}(1.40-1.84) \\
(1.02-1.31) \\
(0.72-1.19)\end{array}$ & $\begin{array}{l}1.14 \\
0.97 \\
0.87\end{array}$ & $\begin{array}{l}(0.98-1.34) \\
(0.83-1.12) \\
(0.67-1.13)\end{array}$ \\
\hline \multirow{7}{*}{$\begin{array}{l}\text { Changes in the } \\
\text { educational } \\
\text { levels }\end{array}$} & $\begin{array}{l}\text { Female upper secondary, male tertiary } \\
\text { Both upper secondaryb } \\
\text { Female upper secondary, male basic }\end{array}$ & $\begin{array}{l}1.36 \\
1.00 \\
0.69\end{array}$ & $\begin{array}{l}(1.17-1.58) \\
(0.58-0.81)\end{array}$ & $\begin{array}{l}1.10 \\
1.00 \\
0.74\end{array}$ & $\begin{array}{l}(0.91-1.33) \\
(0.62-0.88)\end{array}$ \\
\hline & $\begin{array}{l}\text { Female basic, male tertiary } \\
\text { Female basic, male upper secondary } \\
\text { Both basic }\end{array}$ & $\begin{array}{l}1.06 \\
0.73 \\
0.56\end{array}$ & $\begin{array}{l}(0.69-1.64) \\
(0.62-0.87) \\
(0.44-0.72)\end{array}$ & $\begin{array}{l}0.93 \\
0.95 \\
0.83\end{array}$ & $\begin{array}{l}(0.59-1.45) \\
(0.79-1.14) \\
(0.64-1.08)\end{array}$ \\
\hline & $\begin{array}{l}\text { No changes in levels of education }{ }^{b} \\
\text { No change in relative positions }\end{array}$ & $\begin{array}{r}1.00 \\
1.27\end{array}$ & $(1.02-1.58)$ & $\begin{array}{l}1.00 \\
1.01\end{array}$ & $(0.80-1.28)$ \\
\hline & $\begin{array}{l}\text { Towards homogamy, female partner's } \\
\text { educational level increased more }\end{array}$ & 1.09 & $(0.92-1.29)$ & 0.98 & $(0.79-1.21)$ \\
\hline & $\begin{array}{l}\text { Towards homogamy, male partner's educa- } \\
\text { tional level increased more }\end{array}$ & 1.10 & $(0.90-1.34)$ & 0.93 & $(0.75-1.17)$ \\
\hline & $\begin{array}{l}\text { Towards heterogamy, female partner's } \\
\text { educational level increased more }\end{array}$ & 0.83 & $(0.71-0.97)$ & 0.81 & $(0.69-0.96)$ \\
\hline & $\begin{array}{l}\text { Towards heterogamy, male partner's } \\
\text { educational level increased more }\end{array}$ & 1.06 & $(0.84-1.33)$ & 1.01 & $(0.79-1.28)$ \\
\hline \multirow[t]{3}{*}{ Unemployment ${ }^{\mathrm{c}}$} & $\begin{array}{l}\text { Both none }{ }^{b} \\
\text { Female none, male max. } 6 \text { months } \\
\text { Female none, male over } 6 \text { months }\end{array}$ & $\begin{array}{l}1.00 \\
0.88 \\
\mathbf{0 . 4 6}\end{array}$ & $\begin{array}{l}(0.77-1.00) \\
(0.33-0.64)\end{array}$ & $\begin{array}{l}1.00 \\
0.98 \\
0.62\end{array}$ & $\begin{array}{l}(0.85-1.14) \\
(0.43-0.91)\end{array}$ \\
\hline & $\begin{array}{l}\text { Female max. } 6 \text { months, male none } \\
\text { Both max. } 6 \text { months } \\
\text { Female max. } 6 \text {, male over } 6 \text { months }\end{array}$ & $\begin{array}{l}0.96 \\
0.92 \\
\mathbf{0 . 6 4}\end{array}$ & $\begin{array}{l}(0.86-1.07) \\
(0.80-1.07) \\
(0.49-0.83)\end{array}$ & $\begin{array}{l}1.15 \\
1.14 \\
0.95\end{array}$ & $\begin{array}{l}(1.02-1.29) \\
(0.97-1.34) \\
(0.70-1.31)\end{array}$ \\
\hline & $\begin{array}{l}\text { Female over } 6 \text { months, male none } \\
\text { Female over } 6 \text {, male max. } 6 \text { months } \\
\text { Both over } 6 \text { months }\end{array}$ & $\begin{array}{l}0.65 \\
0.45 \\
0.37\end{array}$ & $\begin{array}{l}(0.50-0.85) \\
0.29-0.70 \\
0.22-0.64)\end{array}$ & $\begin{array}{l}0.95 \\
0.74 \\
0.73\end{array}$ & $\left.\begin{array}{l}(0.71-1.28) \\
0.47-1.16 \\
0.41-1.30\end{array}\right)$ \\
\hline \multirow[t]{3}{*}{$\begin{array}{l}\text { Occupational } \\
\text { activityc }\end{array}$} & $\begin{array}{l}\text { Both employed }{ }^{b} \\
\text { Female employed, male student } \\
\text { Female employed, male other }\end{array}$ & $\begin{array}{l}1.00 \\
1.19 \\
\mathbf{0 . 7 6}\end{array}$ & $\begin{array}{l}(0.95-1.49) \\
(0.64-0.91)\end{array}$ & $\begin{array}{l}1.00 \\
1.12 \\
1.13\end{array}$ & $\begin{array}{l}(0.87-1.44) \\
(0.91-1.40)\end{array}$ \\
\hline & $\begin{array}{l}\text { Female student, male employed } \\
\text { Both students } \\
\text { Female student, male other }\end{array}$ & $\begin{array}{l}0.94 \\
0.73 \\
0.74\end{array}$ & $\begin{array}{l}(0.78-1.13) \\
(0.45-1.18) \\
(0.47-1.17)\end{array}$ & $\begin{array}{l}0.90 \\
0.58 \\
0.97\end{array}$ & $\begin{array}{l}(0.73-1.11) \\
(0.34-0.96) \\
(0.60-1.57)\end{array}$ \\
\hline & $\begin{array}{l}\text { Female other, male employed } \\
\text { Female other, male student } \\
\text { Both other }\end{array}$ & $\begin{array}{l}0.73 \\
0.81 \\
0.56\end{array}$ & $\begin{array}{l}(0.65-0.83) \\
(0.52-1.28) \\
(0.44-0.71)\end{array}$ & $\begin{array}{l}0.95 \\
1.00 \\
1.02\end{array}$ & $\begin{array}{l}(0.81-1.11) \\
(0.62-1.61) \\
(0.76-1.39)\end{array}$ \\
\hline \multirow[t]{3}{*}{ Income ${ }^{c}$} & $\begin{array}{l}\text { Both high income } \\
\text { Female high, male medium income } \\
\text { Female high, male low income }\end{array}$ & $\begin{array}{l}1.58 \\
1.27 \\
0.89\end{array}$ & $\begin{array}{l}(1.32-1.89) \\
(0.98-1.65) \\
(0.57-1.38)\end{array}$ & $\begin{array}{l}1.15 \\
1.10 \\
0.72\end{array}$ & $\begin{array}{l}(0.95-1.40) \\
(0.85-1.43) \\
(0.46-1.14)\end{array}$ \\
\hline & $\begin{array}{l}\text { Female medium, male high income } \\
\text { Both medium income } \\
\text { Female medium, male low income }\end{array}$ & $\begin{array}{l}1.21 \\
1.00 \\
0.98\end{array}$ & $\begin{array}{l}(1.06-1.39) \\
(0.82-1.17)\end{array}$ & $\begin{array}{l}1.08 \\
1.00 \\
0.94\end{array}$ & $(0.77-1.15)$ \\
\hline & $\begin{array}{l}\text { Female low, male high income } \\
\text { Female low, male medium income } \\
\text { Both low income }\end{array}$ & $\begin{array}{l}0.93 \\
0.84 \\
0.78\end{array}$ & $\begin{array}{r}(0.80-1.09) \\
(0.73-0.97) \\
(0.66-0.92)\end{array}$ & $\begin{array}{l}0.97 \\
0.92 \\
0.84\end{array}$ & $\begin{array}{l}(0.81-1.15) \\
(0.79-1.09) \\
(0.68-1.04)\end{array}$ \\
\hline \multicolumn{2}{|c|}{$\mathrm{N}$ of cohabiting unions } & \multicolumn{2}{|c|}{3,648} & \multicolumn{2}{|c|}{3,648} \\
\hline \multicolumn{2}{|c|}{$\mathrm{N}$ of contracted marriages } & \multicolumn{2}{|r|}{2,107} & \multicolumn{2}{|c|}{2,107} \\
\hline
\end{tabular}

${ }^{a}$ Controlling for all other socioeconomic characteristics and the control variables presented in Appendix 1.

${ }^{\mathrm{b}}$ Reference category.

c Time-dependent covariate. 
The results are presented as hazard ratios $\left(e^{\beta}\right)$, which indicate the ratio of a group's hazard of marriage to the chosen reference group's corresponding hazard. The reference group's hazard ratio is 1 , and for example a hazard ratio of 1.20 means that the group's hazard of marriage is 20 percent higher than the reference group's hazard. 95 percent confidence intervals for the hazard ratios are also presented.

\section{Results}

Table 2 presents the hazards of marriage by the socioeconomic characteristics of the cohabiting partners. First column of the table presents results from the models including only the variable in question. Second column presents the results of a model including all the socioeconomic characteristics as well as the control variables introduced in Appendix 1.

The most explicit effect of the levels of education of the partners is that the higher the educational level, the higher the marriage rate. Couples where both partners had tertiary-level education at the beginning of the union have the highest rate of marriage. Differences between categories are clearly smaller in the adjusted than in the unadjusted model, which means that part of the effect of educational level on marriage is explained or mediated by other characteristics controlled for in the analysis. In the adjusted model, homogamy seems to have a slight effect on the marriage rate in the study population: if the male partner has a basic-level education, marriage rate is relatively high when the female partner also has a basic-level education. Hence the lowest marriage rate of the educational groups is not among couples where both partners have a low level of education, but among couples where the male partner has a basic-level education and the female partner's educational level is slightly higher, that is, when the female partner has an upper secondary level education. Couples where the female partner has a basic-level and the male partner tertiary-level education, also have a relatively low marriage rate.

As for the changes in the partners' educational levels during the cohabiting union, only one effect arises: the marriage rate is lower among those couples where the female partner's educational level has risen more than the male partner's, and the couple has become more heterogamous with respect to education. Otherwise it has no effect on the transition to marriage whether the educational levels of the partners have changed or not, or whether the change was towards homogamy or heterogamy. In the unadjusted model, couples whose educational levels have increased but no change in the relative positions of the partners has occurred, have a higher marriage rate, but this association is explained by other variables in the analysis.

The most evident effect of the partners' unemployment on the transition to marriage is that the marriage rate is low when the male partner has had over six months of unemployment on average per year and the female partner has not had any. Also couples where both partners have had over six months of unemployment or the female has had over six months and the male maximum six months of unemployment have low marriage rates 
in the study population. In other respects, unemployment has no marriage-depressing effects independent of the other characteristics controlled for in the analysis. Couples where the female partner has had maximum six months of unemployment and the male partner has also had maximum six months or none, have in fact slightly higher marriage rates than couples where neither of the partners has had unemployment.

Controlling for all other variables, the only effect of the partners' occupational activities is that the marriage rate is low when both partners are students. Lower marriage rates of persons in the category 'other' are caused by other variables in the analysis.

Marriage rate mainly increases with higher levels of the partners' income. Other variables in the analysis explain part of the association, but differences between categories persist in the adjusted model. There is only one exception to the association between higher income and higher marriage rate: couples where the female partner has high income and the male partner low income have a very low marriage rate in the study population.

\section{Discussion}

Higher levels of the partners' education were found to promote marriage in the study population. Since several more direct economic factors were controlled for in the analysis, the effect most likely relates to the good long-term material prospects associated with high educational attainment, or some noneconomic aspects of education that increase the gains of contracting a marital union. There may also be educational differentials in the normative climate that affect the probability of formalizing a union. (Kravdal 1999.)

Marriage rate also generally increased with higher levels of the partners' income. This finding supports the view that marriage requires a solid economic foundation. The importance of the wedding party and the ability to cover the short-term expenses of the wedding and may also be of concern: for example, in a recent Finnish survey, for many cohabiters who planned to marry wanting a big wedding party was a reason for marrying (Paajanen 2007), and in a Norwegian survey data from the year 1996, the costs of a wedding were generally considered an important reason for not formalizing a cohabiting union (Kravdal 1999). According to Duvander (1999, 702), the attraction of a clearly defined and regulated union can enhance couples with higher economic resources to choose to marry. On the other hand, differences between the income groups in marriage rates are not vast in the study population.

The only effect of the partners' occupational activities was that the marriage rate was remarkably low when both partners were studying. Previous individual-level studies have reported a low marriage rate when the female partner is studying (Wu and Balakrishnan 1995; Bracher and Santow 1998; Kravdal 1999; Müller 2003), and this effect has often been interpreted to stem from the incompatibility of the roles of a student and a marital partner (see e.g. Thornton et al. 1995, 763). According to Kravdal 
$(1999,76)$, school enrolment can also discourage marriage because of the cohabiters' awareness of availability of alternative partners. Since in this study the effect arises only when both partners are studying, it seems to be enough to encourage marriage that at least one of the partners has an occupational activity that is other than studying.

On the whole, as concluded in previous studies, the transition from cohabitation to marriage seems to require a somewhat solid economic foundation, although the effects of the socioeconomic characteristics are not substantial. In line with results from earlier studies in the Nordic countries (e.g. Bracher and Santow 1998; Duvander 1999; Kravdal 1999), the female partner's socioeconomic qualities also encourage the transition to marriage; not only the male partner's, which has been the conclusion in many studies from the US (Manning and Smock 1995; Smock and Manning 1997; Sanchez et al. 1998; Manning and Smock 2002). It seems that in the Nordic countries, both partners are expected to contribute to the economic basis of the marital union, which is far from surprising, taking the long tradition and high levels of female labour force participation in these countries.

On the other hand, some results in the study support the view that marriage is a more traditional union type than cohabitation. The salience of traditional gender roles in marriage did not, however, appear in the study in the most obvious way, in that couples with conventional combinations of socioeconomic characteristics - that is, where the male partner is in a higher socioeconomic position than the female partner - would have been more likely to marry. Instead, the effect of traditional gender roles was more implicit, as it was the nontraditional combinations of the partners' characteristics that discouraged marriage: cohabiting couples where the female partner had high and the male partner low income had the lowest marriage rate of the different income groups, and the male partner's substantial unemployment discouraged marriage especially when the female partner had not experienced unemployment. The importance of the partners' relative positions also appears in the fact that marriage rate was low if the changes in the educational levels of the partners had strengthened the female partner's position in the union. Thus, despite the largely symmetrical effects of the partners' socioeconomic characteristics on the transition to marriage, traditional gender roles still seem to have some salience in Finnish marital unions (see also Jalovaara 2003, 78). At the same time, it must be noted that whether the found effects actually stem from the different attitudes and value orientations that couples preferring different forms of union have, cannot, obviously, be tested with register data.

Homogamy in the cohabiting partners' characteristics analyzed in this study had little effect on the transition to marriage. Only in the case of levels of education, and specifically among those who had basic-level education, did similarity increase the marriage rate. Hence, the hypothesis posed by Blackwell and Lichter $(2000,2004)$ that predicts more homogamous couples to progress from cohabitation to marriage receives only limited support from the results. 
The connections found in the analysis may not, on the other hand, be entirely causal. Certain third factors that could not be taken into consideration in this study, such as personality traits and social skills, can for example affect both the individual's socioeconomic position and the probability of marrying, and cause the association between higher socioeconomic position and higher marriage rate. Reverse causation, so that for example the forthcoming wedding would cause partners to improve their socioeconomic position instead of the higher socioeconomic position promoting marriage, probably does not have a substantial effect on the results, but at least in the case of income, it may be possible that - since a wedding is often planned months, if not years ahead some couples start to acquire more earnings in advance to fund the wedding.

This study focused on the effects of cohabiting partners' socioeconomic characteristics on the transition from cohabitation to marriage in Finland. The effects of various other social and demographic factors on the transition to marriage, such as the partners' social background and children, will be examined later in another study. How all these factors affect the probability that a cohabiting couple separates, and whether the predictors of separation are different for cohabiting and married couples, is a topic of my further research as well.

\section{Acknowledgements}

I am grateful to Statistics Finland for the permission to use the data (permission number TK-53-747-05), to Kari Pitkänen for supervising my master's thesis, and to Marika Jalovaara for her valuable comments on my thesis and on the manuscript of this article.

\section{References}

Blackwell, Debra L. and Daniel T. Lichter. 2000. Mate Selection among Married and Cohabiting Couples. Journal of Family Issues 21:275-302.

Blackwell, Debra L. and Daniel T. Lichter. 2004. Homogamy among Dating, Cohabiting, and Married Couples. The Sociological Quarterly 45:719-737.

Blair, Sampson Lee and Daniel T. Lichter. 1991. Measuring the Division of Household Labor. Gender Segregation of Housework among American Couples. Journal of Family Issues 12:91-113.

Bracher, Michael and Gigi Santow. 1998. Economic Independence and Union Formation in Sweden. Population Studies 52:275-294.

Clarkberg, Marin. 1999. The Price of Partnering: The Role of Economic Well-Being in Young Adults' First Union Experiences. Social Forces 77:945-968.

Clarkberg, Marin, Ross M. Stolzenberg and Linda J. Waite. 1995. Attitudes, Values, and Entrance into Cohabitational versus Marital Unions. Social Forces 74:609-632.

Cox, D.R. 1972. Regression Models and Life-Tables. Journal of the Royal Statistical Society. Series B (Methodological), 34:187-220.

Davis, Shannon N., Theodore N. Greenstein and Jennifer P. Gerteisen Marks. 2007. 
Effects of Union Type on Division of Household Labor. Do Cohabiting Men Really Perform More Housework? Journal of Family Issues 28:1246-1272.

Duvander, Ann-Zofie E. 1999. The Transition from Cohabitation to Marriage. A Longitudinal Study of the Propensity to Marry in Sweden in the Early 1990s. Journal of Family Issues 20:698-717.

Finnäs, Fjalar. 1995. Entry into Consensual Unions and Marriages among Finnish Women Born between 1938 and 1967. Population Studies 49:57-70.

Jalovaara, Marika. 2003. The Joint Effects of Marriage Partners' Socioeconomic Positions on the Risk of Divorce. Demography 40:67-81.

Jalovaara, Marika. 2007. The Effects of Marriage Partners' Socio-Economic Positions on the Risk of Divorce in Finland. Finnish Yearbook of Population Research 43, Supplement.

Kravdal, Øystein. 1999. Does Marriage Require a Stronger Economic Underpinning than Informal Cohabitation? Population Studies 53:63-80.

Manning, Wendy D. and Pamela J. Smock. 1995. Why Marry? Race and the Transition to Marriage among Cohabitors. Demography 32:509-520.

Manning, Wendy D. and Pamela J. Smock. 2002. First Comes Cohabitation and Then Comes Marriage? A Research Note. Journal of Family Issues 23:1065-1087.

Müller, Rolf. 2003. Union Disruption in West Germany: Educational Homogeneity, Children, and Trajectories in Marital and Nonmarital Unions. International Journal of Sociology 33:3-35.

Mäenpää, Elina. 2007. Homogamia ja suomalaisten nuorten naisten avoliitot. [Homogamy and cohabiting unions of young Finnish women.] Master's thesis, department of sociology, University of Helsinki.

Paajanen, Pirjo. 2007. Perhebarometri 2007. Mikä on minun perheeni? Suomalaisten käsityksiä perheestä vuosilta 2007 ja 1997. Helsinki: Väestöliitto, Väestöntutkimuslaitos E30/2007.

Pitkänen, Kari and Marika Jalovaara. 2007. Perheet ja perheenmuodostus. [Families and family formation.] In Suomen väestö [Population of Finland], 2nd, renewed edition, edited by Koskinen, Seppo, Tuija Martelin, Irma-Leena Notkola, Veijo Notkola, Kari Pitkänen, Marika Jalovaara, Elina Mäenpää, Anne Ruokolainen, Markku Ryynänen and Ismo Söderling, pp. 115-167. Helsinki: Gaudeamus.

Ruokolainen, Anne and Irma-Leena Notkola. 2007. Hedelmällisyys. [Fertility.] In Suomen väestö [Population of Finland], 2nd, renewed edition, edited by Koskinen, Seppo, Tuija Martelin, Irma-Leena Notkola, Veijo Notkola, Kari Pitkänen, Marika Jalovaara, Elina Mäenpää, Anne Ruokolainen, Markku Ryynänen and Ismo Söderling, pp. 115-167. Helsinki: Gaudeamus.

Sanchez, Laura, Wendy D. Manning and Pamela J. Smock. 1998. Sex-Specialized or Collaborative Mate Selection? Union Transitions among Cohabitors. Social Science Research 27:280-304.

Smock, Pamela J. and Wendy D. Manning. 1997. Cohabiting Partners' Economic Circumstances and Marriage. Demography 34:331-341.

Smock, Pamela J., Wendy D. Manning and Meredith Porter. 2005. "Everything's There Except Money": How Money Shapes Decisions to Marry among Cohabitors. 
Journal of Marriage and the Family 67:680-696.

Thornton, Arland, William G. Axinn and Jay D. Teachman. 1995. The Influence of School Enrollment and Accumulation on Cohabitation and Marriage in Early Adulthood. American Sociological Review 60:762-774.

Tzeng, Meei-Shenn. 1992. The Effects of Socioeconomic Heterogamy and Changes on Marital Dissolution for First Marriages. Journal of Marriage and the Family 54:609-619.

Wu, Zheng and T.R. Balakrishnan. 1995. Dissolution of Premarital Cohabitation in Canada. Demography 32:521-532.

$\mathrm{Wu}$, Zheng and Michael S. Pollard. 2000. Economic Circumstances and the Stability of Nonmarital Cohabitation. Journal of Family Issues 21:303-328.

\section{Appendix 1. Control variables in the analysis.}

- Social class of the family during childhood (Employee or self employed / Manual worker / Farmer / Other)

- Structure of the family during childhood (Two-parent family / Other)

- Degree of urbanization of the place of birth (Helsinki region / Other urban / Non-urban)

- Mother tongue (Finnish / Swedish)

- Age homogamy (Female over 2 yrs older / Female 0-2 yrs older / Male 0-2 yrs older / Male 2-4 yrs older / Male 4-6 yrs older / Male over 6 yrs older)

- Marital history (Unmarried / Divorced)

- Woman's age at entry into the cohabiting union (-20 / 21-22 / 23-24 / 25-26 / 27-)

- Duration of the cohabiting union before the follow-up period (Max. 1 year / >1-3 yrs / >3-6 yrs / Over 6 yrs)

- Number of children born to the couple before marriage or the end of the follow-up period (No children / 1 child / 2 children / 3 children or more)

- Whether the woman has children whose father is not the current cohabiting partner (No / Yes)

- Pregnancy (a time-dependent covariate) (No / Yes)

- Children under the age of three (a time-dependent covariate) (No / Yes)

- Degree of urbanization of the municipality of residence (a time-dependent covariate) (Helsinki region / Other urban / Other densely populated / Rural) 
